\title{
Rurality, Alcohol Consumption and Telehealth: Laying the Foundation for Scoping Review
}

\author{
Salifu Yusif* and Michael Erdiaw Kwasie \\ One Touch Research Consult, Australia
}

ISSN: 2689-2707

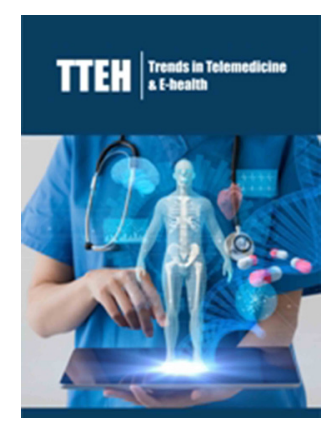

*Corresponding author: Salifu Yusif, OneTouch Research Consult, Australia

Submission: 㘹- October 01, 2019

Published: 留 November 25, 2019

Volume 2 - Issue 1

How to cite this article: Salifu Y, Michael Erdiaw K . Rurality, Alcohol Consumption and Telehealth: Laying the Foundation for Scoping Review. Trends Telemed E-Health 2(1). TTEH. 000529. 2019. DOI: 10.31031/TTEH.2019.02.000529

Copyright@ Salifu Yusif, This article is distributed under the terms of the Creative Commons Attribution 4.0 International License, which permits unrestricted use and redistribution provided that the original author and source are credited.

\begin{abstract}
Alcohol consumption is a contested topic that attracts heated policy debate among key stakeholders at all levels of societies given the magnitude of its impact especially on general health and safety. But there are still very limited studies that focus on a selected vulnerable cohort of alcohol and paying full attention to it in terms of cumulative studies towards evidence-based intervention. This study, therefore, serves to prepare grounds for scoping, systematic and meta-analysis on alcohol, social group, young adults and the potential of telehealth to serve as reliable care intervention for the high-risk. Our initial findings suggest that rurality, age and social groups are potential mapping concepts for scoping reviews.
\end{abstract}

Keywords: Alcohol consumption; Rurality; Social group; Telehealth

\section{Introduction}

Globally, the issue of alcohol consumption and health issues have attracted the attention of health practitioners, scholars, policy makers and governments across the globe. The consequences of alcohol abuse and its health implications have been recorded in both developed and developing nations. The consequences of alcohol abuse spans across disability, diseases and death in all societies from a public health assessment [1]. This is of a particular concern to Australia, where the National Drug Strategy survey, 2016 revealing that $17 \%$ of Australians aged 12 or older consumed alcohol beyond reasonable levels [2], equivalent of taking more than two standard drinks (10g of alcohol) in a day [3]. Nearly 50\% of 603 online survey among young adults aged 18-24 met the Alcohol Use Disorders Identification Test (AUDIT) (AUDIT) threshold [4]. A national study into the effects of alcohol on third-party in Australia suggests that about a third of Australian workers have had to endure some sort of negative impact of drinking from co-workers through extra working hours to cover for others, translating into an estimated $\$ 453$ million cost to the Australian economy [5]. The severity of increasing alcohol consumption among vulnerable cohorts and its associated health consequences are on the rise. There is, however, a lack of studies that lay foundation for cumulative evidence-based cohort studies on a chosen vulnerable group. Thus, this paper is relevant and timely as it attempts to lay the ground for scoping review, systematic and meta-analytic studies focusing on alcohol consumption, young adults, rurality and telehealth.

\section{Social Group and Rurality}

Sadly, most studies have found this evidence of high-risk drinking within rural populations compared with their urban counterparts [6], more so among university students. Specifically, this pattern of prevalence has been higher among people from rural and remote dwelling. Studies conducted by Quine \& Bernard [7], Fuller \& Edwards [8], Bourke [9] suggest that structural disadvantages in rural areas such as limited recreational facilities and limited healthcare services impact adversely on health outcomes, particularly mental health outcomes, and contribute to risk-taking behaviours. Particularly, strong correlations have been found between difficulties in accessing healthcare services, lack of recreation, boredom and loneliness and alcohol dependency $[10,11]$. Limited access to health services continue to remain a key alcohol drinking risk factor in rural and regional Australia Its components include but not limited to availability of doctors, alcohol counselling; alcohol treatments and psychologist; lack of proper transportation coupled with long travel distance and costs $[12,13]$ in the wake of easy-reach alcohol outlets. Furthermore, in rural communities, there 
is a general lack of privacy, a situation where health care providers such as councillor or nurse is known by nearly all community members and vice versa [12]. This familiarity has the potential of making locals uncomfortable to talk to healthcare providers about their drinking behaviour for fear of stigmatization.

\section{Age Cohort}

Another principal risk factor is social motives, which triggers drinking among youth and young adults from the rural/remote background and is associated with a strong drinking culture. Community members often use alcohol as a way of getting together with friends, relaxing and celebrating occasion due to limited choices for fun and socializing activities for young adults, which leads to boredom [12]. For example, Livingston \& Laslett [14], Cooper SM et al. [15] found that about $19 \%$ and $31 \%$ of adolescents and young adults (16- to 24-years old) in metropolitan areas and remote/very remote regions respectively engage in risky drinking. Similarly, Rickwood \& George [4] also found that alcohol harm was more prevalent among first-year university students living on campus from rural and regional Australian settings. Characterising this problem is also a general low socio-economic status of rural/ remote communities/families that has also been seen as risk-factor to high level alcohol consumption among families as a way of coping with stress from idleness or boredom [16].

The lack of timely qualified alcohol counselling and treatment providers in rural communities $[12,13]$ impact adversely on health outcomes, particularly mental health outcomes, and contribute to risk-taking behaviours [17]. However, recruitment and sustainability of medical workforce in rural and sparsely populated communities remain protracted challenges not only in developing countries but also in developed ones [18]. Australia is no exception to this challenge. Rural Australians, have, however, reportedly benefited from enhanced access and quality of healthcare through telemedicine and telehealth [19] and should be considered by health-service policy makers and providers as a means to redressing the above-mentioned structural imbalance between urban and rural communities [17].

\section{Telehealth}

According to the World Health Organization, Telehealth is "the practice of healthcare using interactive audio, visual and data communications. This includes healthcare delivery, diagnoses, consultation and treatment, as well as education and transfer of medical data" [20]. Brief Interventions (BIs) for alcohol consumption have increasingly be carried out via Telehealth [2124] and to manage a number of chronic diseases such as cancer [25]; diabetes [26]; and tele psychiatry [27-31] in the context of Brief Intervention (BI) and Motivational Interviewing (MI). A general challenge, though, for the use and implementation of telehealth as health services intervention has been low acceptance, not only by healthcare consumers but also healthcare providers in the context of fears surrounding health information security vulnerabilities by consumers and liability concerns from healthcare providers [3250] as well as jurisdiction and reimbursement for services [51].
According to the WHO, BIs are "practices that aim to identify a real or potential alcohol or other drug problem and motivate an individual to do something about' [52]. Although the effectiveness of brief intervention has been questioned in their application in real world cases, it appears to work well with people who are 'at risk' of dependence rather than those are already seen to be dependent [3]. BIs have actually been commended for reducing alcohol related problems, healthcare use and treatment and costs as well as presentations at emergency departments [8] and in situations where providers of this service have received training, studies have also found them to be ineffective in primary care and requires training of providers $[53,54]$.

Boredom has been conceptualised as a state of understimulation, under-arousal, lack of momentum or a lack of psychological involvementassociated with dissatisfaction in the task situation "Several studies have supported the use of positive leisure experiences to assist the individual's interpersonal interactions, sense of control and social skills" [55]. These studies opine that participation in positive leisure activities that include but are not limited to soccer, handball, karate, swimming, drama, dancing, athletics, gymnastics, and scouting [56] where the young adult has the freedom to choose, and feels in control has the potential to reduce and abuse as is the case with most rural Australia.

Theincreasehealthcare services intervention will fundamentally emphasis on making healthcare services - doctors, councillors available and easy to reach. To achieve this objective, given the low population nature of rural communities, telehealth is proposed as an intervention. Telehealth, tele-counselling in this study is the provision of alcohol counselling services via telephone or interactive tele-video links [16]. These counselling services will be offered to senior high schoolies and young adults in selected communities. A partnership with local schools, relevant community NGOs and strong engagement with community leadership/parents will help identify/contact potential beneficiaries of this intervention. Given that this intervention focuses on reducing among young adults, it fits well with primary level of health promotion. This will identify high-risk high schoolies and young adults and engage with them regarding alcohol consumption on one the hand while promoting good health on the other hand. Although, telehealth is generally used for health care services, it has emerged in recent years as an approach for behavioural health services with promising outcomes [57]. Telehealth has exhibited the ability to reduce inequitable access to healthcare and the poorer health status of many rural Australians now face as with contributing to addressing the ongoing recruitment and retention of rural work health workforce [58]. Additionally, tele-counselling is believed to overcome not only the geographic barriers to treatment, but also concerns with confidentiality and stigma, which may be particularly significant in small rural communities $[59,60]$ as identified earlier. As such, this intervention is expected to facilitate access to healthcare needs of designated individuals and young adults, specifically, high school seniors and related population groups with the specific intent of providing the right care in the right place at the right time [61]. 


\section{Conclusion}

In conclusion, whereas high alcohol consumption has old root in many rural cultures and among its residents, the emerging important role of telehealth in ameliorating the current levels is very much evidenced. We share the hope that telehealth has the potential to impact policy and behavioural changes in the scope of alcohol consumption among rural folks. The shared knowledge in this paper offers theoretical understandings for future empirical research studies in this field.

\section{References}

1. (2010) Alcohol and Public Policy Group. Alcohol: No ordinary commodity-a summary of the second edition. Addiction 105(5): 769779.

2. (2017) Australian Institute of Health and Welfare, National drug strategy household survey 2016: Detailed findings. Australia.

3. Rodgers C (2018) Brief interventions for alcohol and other drug use. Australian prescriber 41(4): 117-121.

4. Rickwood D (2011) Harmful alcohol use on campus: Impact on young people at university. Youth Studies Australia 30(1): 34.

5. Dale C, Livingston M (2010) The burden of alcohol drinking on coworkers in the Australian workplace. Medical journal of Australia 193(3): 138-140.

6. Miller P, Coomber K, Staiger P, Zinkiewicz L, Toumbourou JW (2010) Review of rural and regional alcohol research in Australia. Australian Journal of Rural Health 18(3): 110-117.

7. Quine S, Bernard D, Booth M, Kang M, Usherwood T, et al. (2003) Health and access issues among Australian adolescents: A rural-urban comparison. Rural Remote Health 3(3): 245.

8. Fuller J, Edwards J, Procter N, Moss J (2000) How definition of mental health problems can influence help seeking in rural and remote communities. Australian Journal of Rural Health 8(3): 148-153.

9. Bourke L (2001) Australian rural consumers perceptions of health issues. Australian Journal of Rural Health 9(1): 1-6.

10. Katz AM, Morgan, Sherlock S (1981) Alcoholism treatment in a medical setting. Journal of studies on alcohol 42(1): 136-143.

11. Geerlings P, Lesch O (1999) Introduction: Craving and relapse in alcoholism: Neuro bio-psychosocial understanding. Alcohol and Alcoholism 34(2): 195-196.

12. (2019) Department of Health Australia. Alcohol in rural and remote communities. Australia.

13. Booth B, Curran G (2006) Variations in drinking patterns in the rural South: Joint effects of race, gender, and rural residence. The American Journal of Drug and Alcohol Abuse 32(4): 561-568.

14. Livingston M, Laslett A, Dietze P (2008) Individual and community correlates of young people's high-risk drinking in Victoria, Australia. Drug Alcohol Dependence 98(3): 241-248.

15. Cooper SM, Nargis S (2009) Correlates of risky alcohol consumption in regional and remote Australia, in $10^{\text {th }}$ National Rural Health Conference. Australia.

16. Coomber K, Toumbourou JW, Miller P, Staiger PK, Hemphill SA, et al. (2011) Rural adolescent alcohol, tobacco, and illicit drug use: A comparison of students in Victoria, Australia, and Washington State, United States. The Journal of Rural Health 27(4): 409-415.

17. Bellg A, Borrelli B, Resnick B, Hecht J, Minicucci DS, et al. (2004) Enhancing treatment fidelity in health behavior change studies: Best practices and recommendations from the NIH behavior change consortium. Health Psychology 23(5): 443-451.
18. Irving M, Stewart R, Spallek H, Blinkhorn A (2018) Using teledentistry in clinical practice as an enabler to improve access to clinical care: A qualitative systematic review. Journal of Telemedicine and Telecare 24(3): 129-146.

19. Moffatt J, Eley D (2010) The reported benefits of telehealth for rural Australians. Australian Health Review 34(3): 276-281.

20.(1993) Telemedicine: Assessing the Kansas environment. Kansas department of health and environment. USA.

21. Boudreaux E, Haskins B, Harralson T, Bernstein E (2015) The remote brief intervention and referral to treatment model: Development, functionality, acceptability, and feasibility. Drug and Alcohol Dependence 155: 236-242.

22. (2015) The hospital drug \& alcohol consultation liaison model of care. Australia.

23. King S (2015) A comparison between telehealth and face-to-face brief alcohol interventions for college students in Graduate College. USA.

24. Staton TM, Wahler E, Webster JM, Godlaski T, Freeman R, et al. (2012) Telemedicine-based alcohol services for rural offenders. Psychological Services 9(3): 298-309.

25. Selva N, Olver SI, Shepherd L (2007) Beyond the bush telegraph: Telehealth for remote cancer control and support in Cancer Forum. Cancer forum 31(2): 77-80.

26. Bursell SL, Brazionis, Jenkins A (2012) Telemedicine and ocular health in diabetes mellitus. Clinical and Experimental Optometry 95(3): 311327.

27. Cowain T (2001) Cognitive-behavioural therapy via videoconferencing to a rural area. Australian \& New Zealand Journal of Psychiatry 35(1): 62-64.

28. Buist A, Coman G, Silvas A, Burrows G (2000) An evaluation of the telepsychiatry programme in Victoria, Australia. Journal of Telemedicine and Telecare 6(4): 216-221.

29. Souza DR (2000) Telemedicine for intensive support of psychiatric inpatients admitted to local hospitals. Journal of Telemedicine and Telecare 6(1 suppl): 26-28.

30. Gelber H, Alexander M (1999) An evaluation of an Australian videoconferencing project for child and adolescent telepsychiatry. Journal of Telemedicine and Telecare 5(1 suppl): 21-23.

31. Frueh BS, Henderson, Myrick H (2005) Telehealth service delivery for persons with alcoholism. Journal of Telemedicine and Telecare 11(7): 372-375.

32. Qureshi Q (2014) E-readiness: A crucial factor for successful implementation of E-health projects in developing countries like Pakistan. Public Policy and Administration Research 4(8): 97-103.

33. Oio S, Olugbara 00, Ditsa G, Adigun MO, Xulu SS (2007) Formal model for e-healthcare readiness assessment in developing country context. Innovations in Information Technology.

34. Nahm E, Blum K, Scharf B, Friedmann E, Thomas S, et al. (2008) Exploration of patients readiness for an eHealth management program for chronic heart failure: A preliminary study. Journal of Cardiovascular Nursing 23(6): 463-471.

35. Lua P, Ibrahim U (2015) Perception and readiness of community pharmacists on the use of mobile smart phone as a health monitoring tool. Education in Medicine Journal 7(3)

36. Jones R (2013) Development of a questionnaire and cross-sectional survey of patient e-health readiness and e-health inequalities. Med 2(2): e9.

37. Duplaga M (2015) A cross-sectional study assessing determinants of the attitude to the introduction of eHealth services among patients suffering from chronic conditions. BMC Medical Informatics and Decision Making 15(1): 33. 
38. Légaré É, Vincent C, Lehoux P, Anderson D, Kairy D, et al. (2010) Telehealth readiness assessment tools. Journal of Telemedicine and Telecare 16(3): 107-109.

39. Gaetano DN, Shore J (2015) Conducting a telehealth needs assessment. Clinical Videoconferencing in Telehealth pp. 23-54.

40. Jafari J, Hossein K, Soleiman A, Nabil Z, Italo M (2015) Investigating readiness to use Internet and mobile services of diabetic patients of a middle-income country. Peer J Pre Prints 3: e1359.

41. Amatayakul M (2005) EHR? Assess readiness first: There's no denying interest in electronic health records is increasing. Healthcare Financial Management 59(5): 112-114.

42. Habibi KM, Safdari R, Bouraghi H (2015) Nurses readiness and electronic health records. Acta Informatica Medica 23(2): 105-107.

43. Scott R, Ndumbe P, Wootton R (2005) An e-health needs assessment of medical residents in Cameroon. Journal of Telemedicine and Telecare 11(suppl 2): 78-80.

44. Strauss A (2015) A user needs assessment to inform health information exchange design and implementation. BMC Medical Informatics and Decision Making 15(1): 81

45. Tariq A, Akter S (2011) An assessment of m-Health in developing countries using task technology fit model. Association for Information Systems pp. 1-12.

46. Touré M, Poissant L, Swaine B (2012) Assessment of organizational readiness for e-health in a rehabilitation centre. Disability and rehabilitation 34(2): 167-173.

47. Qureshi Q Ahmad I, Nawaz A (2012) Readiness for e-health in the developing countries like Pakistan. Gomal Journal of Medical Sciences $10(1)$.

48. Okazaki S, Castañeda J, Sanz S (2013) Clinicians assessment of mobile monitoring: A comparative study in Japan and Spain. Medicine 2(2): e11.

49. Justice E (2012) E-healthcare/Telemedicine readiness assessment of some selected states in western Nigeria. International Journal of Engineering and Technology 2(2).

50. Kgasi M, Kalema B (2014) Assessment E-health readiness for rural
South African areas. Journal of Industrial and Intelligent Information 2(2): 131-135.

51. Jennett P, Gagnon M, Brandstadt H (2005) Preparing for success: Readiness models for rural telehealth. Journal of Postgraduate Medicine 51(4): 279-285.

52. Rodgers C (2018) Brief interventions for alcohol and other drug use. Australian prescriber 41(4): 117-121.

53. Aalto M, Pekuri P, Seppä K (2003) Obstacles to carrying out brief intervention for heavy drinkers in primary health care: A focus group study. Drug and Alcohol Review 22(2): 169-173.

54. Vinson D (2000) Alcohol-related discussions in primary care a report from ASPN (Ambulatory Sentinel Practice Network). Journal of Family Practice 49(1): 28-33.

55. Patterson I, Pegg S (1999) Nothing to do: The relationship between leisure boredom and alcohol and drug addiction: Is there a link to youth suicide in rural Australia? Youth Studies Australia 18(2): 24-29.

56. Leversen I, Danielsen AG, Birkeland MS, Samdal O (2012) Basic psychological need satisfaction in leisure activities and adolescents life satisfaction. Journal of Youth and Adolescence 41(12): 1588-1599.

57. Staton TM, Wahler E, Webster JM, Godlaski T, Freeman R, et al. (2012) Telemedicine-based alcohol services for rural offenders. Psychological Services 9(3): 298-309.

58. Moffatt J, Eley D (2010) The reported benefits of telehealth for rural Australians. Australian Health Review 34(3): 276-281.

59. Baca C (2007) Telecounseling in rural areas for alcohol problems. Alcoholism Treatment Quarterly 25(4): 31-45.

60. Molfenter T, Boyle M, Holloway D, Zwick J (2015) Trends in telemedicine use in addiction treatment. Addiction Science \& Clinical Practice 10(1): 14.

61. Darkins A, Ryan P, Kobb R, Foster L, Edmonson E, et al. (2008) Care coordination/Home telehealth: The systematic implementation of health informatics, home telehealth, and disease management to support the care of veteran patients with chronic conditions. Telemedicine and E-Health 14(10): 1118-1126. 